\title{
The treatment of lupus nephritis by methyl prednisolone pulse therapy
}

\author{
S. DosA* \\ M.D., M.R.C.P. \\ W. LAWLER \\ M.B., Ch.B. \\ N. P. MALLICK \\ B.Sc., M.B., F.R.C.P. \\ S. A. CAIRNS
B.Sc., M.B., M.R.C.P. \\ I. N. SLOTKI \\ B.Sc., M.B., Ch.B \\ Department of Renal Medicine, Manchester Royal Infirmary, and \\ Department of Pathology, University of Manchester
}

\begin{abstract}
Summary
Four patients with proliferative glomerulonephritis due to systemic lupus erythematosus were treated with intravenous methyl prednisolone 'pulse' therapy. In all, eight courses of therapy were given, three for acute oliguric renal failure; and on each occasion there was a good response to the treatment. Clinical, histological and immunological details of the patients are presented. The diagnosis, treatment, and monitoring of disease activity in lupus nephritis are discussed in the light of this experience.
\end{abstract}

\section{Introduction}

Renal involvement in systemic lupus erythematosus (SLE) has been studied extensively and death from frenal failure is one of the serious consequences of the disease (Dubois and Tuffanelli, 1964; Estes and Christian, 1971; Feng, Cheah and Lee, 1973). Renal histopathological changes are valuable both as a prognostic indicator and in monitoring disease activity. The prognosis is broadly proportional to the extent of glomerular proliferative changes and acute renal failure due to diffuse proliferative glomerulonephritis with crescent formation is almost invariably associated with early death (Baldwin et al., 1970; Pollack, Pirani and Kark, 1961; Baldwin and Gallo, 1975).

Whilst oral corticosteroids alone are of some benefit in the treatment of diffuse proliferative lupus nephritis (LN) (Pollack et al., 1961, 1973; Ackerman, 1970) other forms of therapy have recently been advocated, especially for patients with severe renal failure. Some success has been reported with combination therapy consisting of steroids, immunosuppressants, dipyridamole and anticoagulants, but morbidity and mortality attributable to therapy do occur (Ponticelli et al., 1974; Brown et al.,

* Present address: Department of Nephrology, University of Cincinnati, U.S.A.

Requests for reprints: Dr N. P. Mallick, Consultant Physician, Department of Renal Medicine, Manchester Royal Infirmary, Oxford Road, Manchester 13.
1974). Encouraging preliminary results have been $\frac{3}{-9}$. obtained with plasmapheresis (Jones et al., 1976) but $\AA$ this technique is not available in all centres, is timeconsuming and costly and its effectiveness needs $\mathrm{G}$ further evaluation. A simple therapeutic regime is clearly preferable.

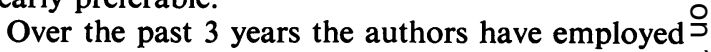
intravenous methyl prednisolone (MP) pulse therapy $\vec{C}$ in cases of SLE with severe renal involvement. Here $\mathbb{D}$ they describe their results in four patients with $\underset{\mathbb{\Phi}}{\mathbb{\Phi}}$ diffuse proliferative $\mathbf{L N}$, two of whom presented with acute oliguric renal failure.

\section{Case reports}

Details of the four patients are summarized Table 1.

\section{Case 1}

In 1967, at the age of 19 years, a Chinese girl 응 developed acute renal failure during her first preg- $\stackrel{\Phi}{\varrho}$ nancy. Renal biopsy showed diffuse proliferative $\overrightarrow{\vec{O}}$ glomerulonephritis with crescents. The pregnancy 3 was terminated and, with oral steroids and azathioprine, renal function improved. Proteinuria persisted and she remained on high doses of oral하 steroids. Her third pregnancy was terminated in 1971 following an abrupt deterioration in renal function. By 1972 she was Cushingoid and hypertensive. The steroids were tailed off and by May $ᄋ$ 1973 she was asymptomatic. At this time the anti- $₹$ nuclear factor (ANF) became positive, there was 음 depletion of complement components, creatinine $D$ clearance was $50 \mathrm{ml} / \mathrm{min}$ and heavy proteinuria, $9 \mathrm{~g} / 24 \mathrm{hr}$, persisted. Repeat renal biopsy showed N mesangial proliferation with crescents progressing to sclerosis. In July 1974 she had a further episode $O$ of acute renal failure. She was treated with methyl $\underset{\omega}{ }$ prednisolone $250 \mathrm{mg}$ i.v. for 12 days and cyclophosphamide and chlorambucil. There was sub- 0 stantial recovery of renal function and anti-DNA antibody and complement levels improved (Fig. 1). $\stackrel{?}{?}$ She had a further episode of acute oliguric renal to 


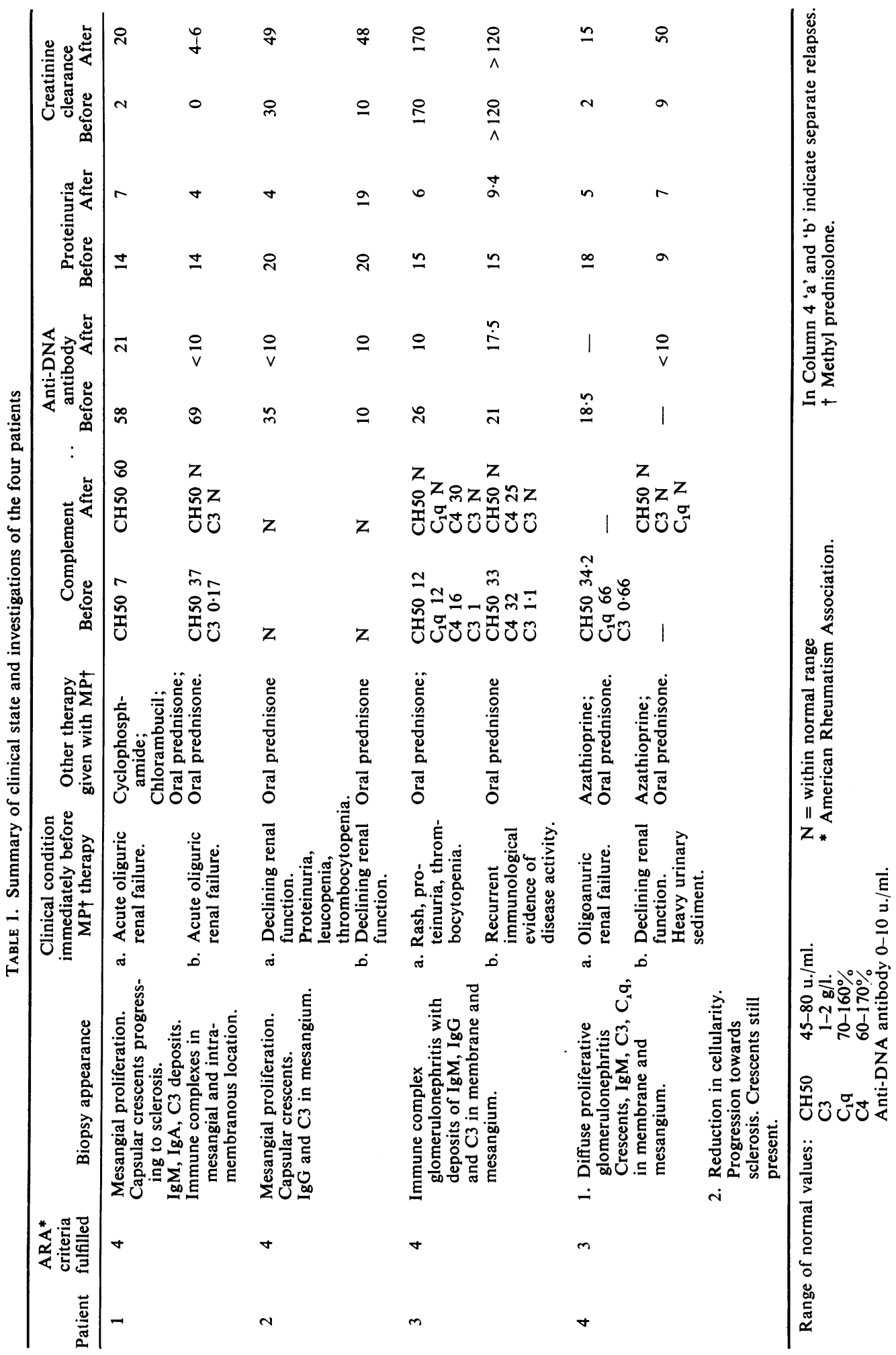




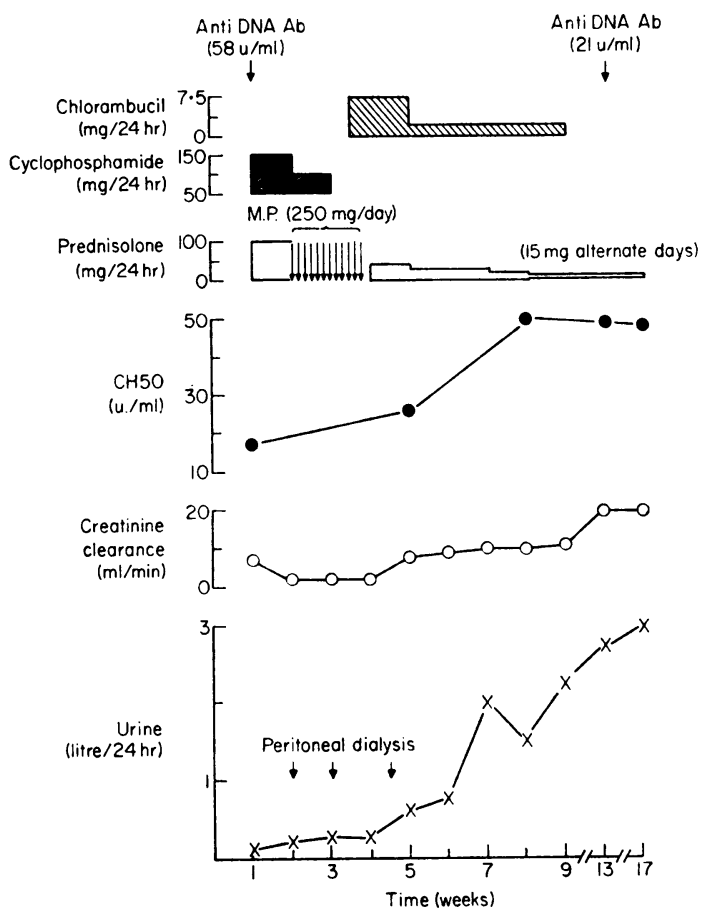

Fig. 1. Clinical Course - Case 1.

failure in August 1976 when renal biopsy showed widespread glomerulosclerosis. She received a further course of methyl prednisolone with recovery of some renal function which was accompanied by a return to normal of anti-DNA antibody, CH50 and C3 levels. Following this episode she managed well on diet until August 1977 when she died in end stage renal failure.

\section{Case 2}

A 49-year-old woman presented in October 1975 with a nephrotic syndrome and microscopic haematuria. The ANF was negative and serum complement components and anti-DNA antibody normal. Renal biopsy showed mesangial proliferation with crescents. By June 1976 her creatinine clearance had declined in 9 months from 50 to $30 \mathrm{ml} / \mathrm{min}$ and she had developed leucopenia and thrombocytopenia. The ANF was now positive and the anti-DNA antibody was raised. Following methyl prednisolone one $\mathrm{g}$ i.v. daily for 5 days the white cell and platlet counts and anti-DNA antibody were normal and the creatinine clearance had risen to $50 \mathrm{ml} / \mathrm{min}$. A further course of methyl prednisolone was given in October 1976 when her creatinine clearance fell abruptly to $10 \mathrm{ml} / \mathrm{min}$. The anti-DNA antibody and serum complement levels were normal. The creatinine clearance rose following the course to $48 \mathrm{ml} / \mathrm{min}$.
Case 3

A 15-year-old girl dcveloped SLE in September 1975 when she presented with a facial rash and nephrotic syndrome. She had thrombocytopenia and a circulating antifactor II antibody. The ANF was positive, anti-DNA antibody raised and $\mathrm{CH} 50, \mathrm{C}_{1} \mathrm{q}$, 당 $\mathrm{C} 4$ and $\mathrm{C} 3$ low. Her condition partially responded $\frac{\bar{\sigma}}{\mathrm{s}}$ to oral prednisolone, $100 \mathrm{mg} /$ day but proteinuria $\overparen{\nabla}$ persisted. The anti-DNA antibody remained raised and there was continuing evidence of complement activation. She became Cushingoid and azathioprine $\vec{\circ}$ and chloroquine therapy were added. When her $\vec{\overrightarrow{ }}$ coagulation defect had resolved a renal biopsy showed mesangial proliferation and crescent formation. Following a recurrence of her nephrotic syndrome, facial rash and thrombocytopenia in June 1976 she received a course of methyl prednisolone. The proteinuria declined, creatinine clearance rose $\mathcal{G}^{-}$ and the platelet count returned to normal. With the exception of a persistently low $\mathrm{C} 4$, complement $\underset{\infty}{\mathbb{N}}$ components and anti-DNA antibody were normal. 을 The patient was maintained on low doses of oral prednisolone until October 1976 when a rising anti- $\mathcal{C}$ DNA antibody and falling $\mathrm{CH} 50$ and $\mathrm{C} 3$ levels $\frac{\mathbb{D}}{O}$ prompted a further methyl prednisolone course which reversed the changes. Now (1977) the feature o of Cushing's syndrome have regressed and the facial erythema has almost resolved.

\section{Case 4}

A 57-year-old man presented in August 1976 with oligo-anuric renal failure, oedema and hypertension. The antinuclear factor was negative but anti-DNA antibody raised and $\mathrm{CH} 50, \mathrm{C}_{1} \mathrm{q}$ and $\mathrm{C} 3 \stackrel{\circ}{\mathrm{D}}$ low. There were red cells and granular casts in the urine. Renal biopsy showed diffuse proliferative glomerulonephritis with crescents. Oliguria persisted despite oral steroids and azathioprine so he received a 5-day course of methyl prednisolone followed by low dose oral steroids and azathioprine (Fig. 2). Renal function improved, serum complement levels returned to normal and urinary sediment cleared. A further course of methyl prednisolone was given in September 1976 when renal function declined and urinary cell and cast excretion recurred. Recovery was again observed. A renal biopsy showed less cellularity with progression towards sclerosis. Crescents were still present.

\section{Discussion}

The diagnosis of SLE is often difficult at initial $N$ presentation. Cohen and Canoso (1972) found that $\omega$ only $67 \%$ of their patients fulfilled the American Rheumatism Association (ARA) criteria (Cohen, $\stackrel{0}{\odot}$ Reynolds and Frankin, 1971) for systemic lupus $\stackrel{\Phi}{\sim}$ erythematosus at first, whereas 7 years later $94 \%$ did so. The present cases accord with this finding. Only 

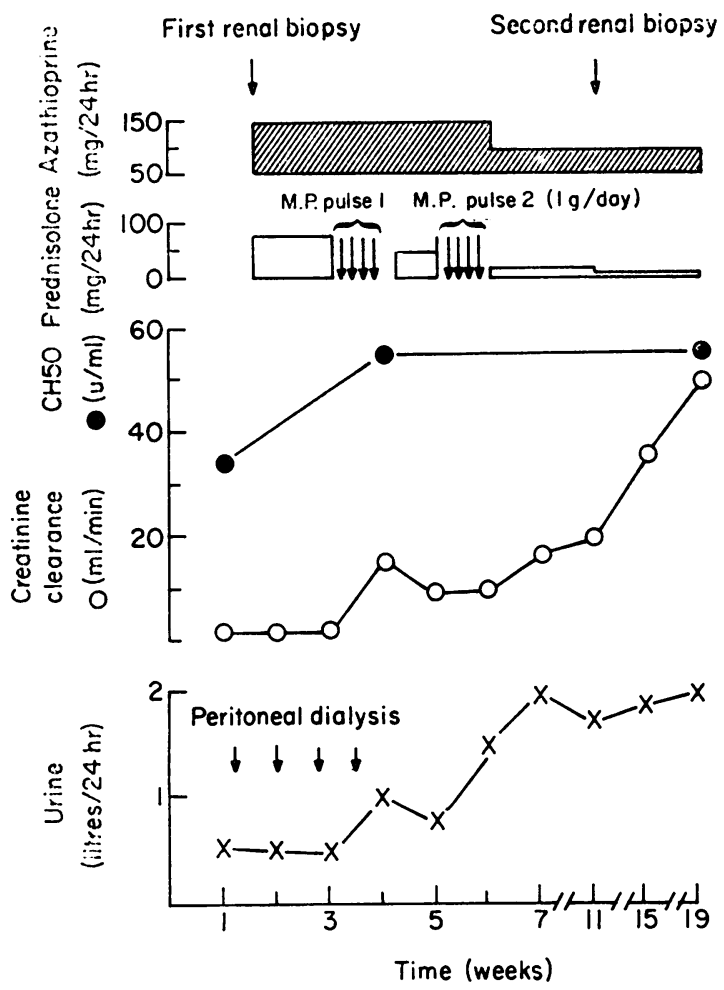

FIg. 2. Clinical Course-Case 4.

one of the present cases fulfilled the American Rheumatism Association criteria at presentation whereas now all but one do so. In a larger series, twelve out of 260 patients presenting with proteinuria developed a positive ANF at a later stage of their illness, the diagnosis of SLE eventually being established in five of these cases (Cairns, Dosa and Mallick, unpublished).

The criteria for diagnosing systemic lupus erythematosus are becoming more precise but difficulties still arise (Davis et al., 1973). Serum complement and anti-DNA antibody levels are affected in systemic lupus erythematosus and their value as markers of disease activity has been extensively reviewed (Schur and Sanderson, 1968; Epstein, 1973; Schur, 1975; Hughes, 1975; Bardana et al., 1975; Cameron et al., 1976). The LE cell phenomenon is a less sensitive index of the presence or activity of its eponym than was previously supposed (Sharp et al., 1971).

The varying natural history of SLE makes assessment of therapy difficult; particularly in cases with only mild renal involvement where prolonged survival is usual (Baldwin et al., 1970; Zweiman et al., 1968 ) but is easier to judge in patients with severe diffuse proliferative lesions. In such cases treatment with corticosteroids in a dose of $40-60 \mathrm{mg} / \mathrm{day}$ over prolonged periods has improved survival significantly but steroid toxicity is frequent (Feng et al., 1973; Pollack et al., 1961, 1973). Indeed, it contributes to early mortality and may be responsible for some of the late morbidity and mortality of lupus patients (Bulkley and Roberts, 1975; Urowitz et al., 1976). Gary, Maher and Schreiner (1967) found that intensive therapy sufficient to suppress disease activity during the acute phase may be safely followed by minimal daily steroid therapy. Cathcart et al. (1976) showed that methyl prednisolone pulse therapy results in rapid improvement in renal function and reversal of associated immunological abnormalities, and that these benefits are sustained with low dose maintenance steroid therapy. Recent evidence suggests that methyl prednisolone therapy reduces the level of circulating soluble immune complexes in patients with lupus nephritis even when large doses of oral prednisolone fail to do so, and that this fall correlates well with improvement in clinical activity of the disease (Levinsky, Cameron and Soothill, 1977).

The clinical presentation and type of renal involvement in the present patients suggested a poor prognosis, since two of them were originally in acute oliguric renal failure and, in all, the biopsy appearances were of severe diffuse proliferative lupus nephritis with glomerular crescent formation. Case 1 (initially thought to have idiopathic glomerular disease) is possibly unique in having suffered and survived four episodes of oliguric renal failure due to lupus nephritis. Therapy with oral prednisolone produced benefit but at a price. She developed so grotesque an appearance (florid Cushingoid habitus with extensive striae) that she was rejected by her husband and family. Later episodes were successfully treated with methyl prednisolone pulses combined with maintenance low dose oral prednisolone and there were no significant side effects. In Case 4, who was initially anuric, methyl prednisolone pulse therapy produced a dramatic improvement in renal function and a subsequent relapse was rapidly reversed by a further pulse.

Despite improvement in the glomerular filtration rate following methyl prednisolone only a transient reduction in proteinuria was observed in the four patients but, as noted previously, the level of proteinuria is a poor guide to renal disease activity (Pollack et al., 1961; Ackerman, 1970).

The effect of methyl prednisolone pulse therapy on the immunological abnormalities associated with lupus nephritis was impressive. In Case 3, serum complement levels, which had remained low during several months of oral steroid therapy were, with the exception of $\mathrm{C} 4$, normal within a few weeks of starting pulse therapy. A similar response was 
obtained in all the patients with evidence of complement consumption. In all cases, there was a sharp fall in anti-DNA antibody titres with therapy.

In Case 4, despite clinical and immunological improvement a repeat renal biopsy two weeks after the second pulse showed only slight decrease in cellularity and progression towards sclerosis. The findings on immunofluorescence remained unchanged and on electron microscopy there was still extensive immune complex deposition in mesangial and intramembranous locations. It seems likely that factors other than the simple presence of immune complexes play an important part in the renal damage of lupus nephritis and are altered by methyl prednisolone therapy.

Extrarenal manifestations of disease were suppressed in the present patients even when this had not been achieved by oral steroids. No side effects associated with methyl prednisolone therapy were observed and because of the lower maintenance steroid dosage, Cushingoid features subsequently regressed in two of the patients. Methyl prednisolone pulse therapy is effective in the treatment of severe proliferative lupus nephritis regardless of the degree of renal impairment and should be considered as the first line of treatment for this condition. Response to such therapy appears to be rapid and, because of its simplicity and lack of side effects, it can be readily repeated if relapse occurs. In the authors' experience, once remission has been achieved it can be maintained with low dose daily or alternate day maintenance steroid therapy which produces few side effects.

\section{References}

ACKerman, G.L. (1970) Alternate-day steroid therapy in lupus nephritis. Annals of Internal Medicine, 72, 511.

Baldwin, D.S. \& Gallo, G.R. (1975) Lupus nephritis. Clinics in Rheumatic Diseases, 1, 639.

Baldwin, D.S., Lowenstein, J., Rothfield, N.F., Gallo, G. \& McCluskey, R.T. (1970) The clinical course of the proliferative and membraneous forms of lupus nephritis. Annals of Internal Medicine, 73, 929.

Bardana, E.J., Harbeck, R.J., Hoffman, A.A., Pirofsky, B. \& CARR, R.I. (1975) The prognostic and therapeutic implications of DNA: anti-DNA antibody immune complexes in systemic lupus erythematosus (S.L.E.). The American Journal of Medicine, 59, 515.

Brown, C.B., Turner, D., OgG, C.S., Wilson, D., Cameron, J.S., Chantler, C. \& Gill, D. (1974) Combined immunosuppression and anticoagulation in rapidly progressive glomerulonephritis. Lancet, ii, 1167.

BulKLEY, B.H. \& RoBerTS, W.C. (1975) The heart in systemic lupus erythematosus and the changes induced in it by corticosteroid therapy. The American Journal of Medicine, 58, 243.

Cameron, J.S., Lessof, M.H., Ogg, C.S., Williams, B.D. \& Williams, D.G. (1976) Disease activity in the nephritis of systemic lupus erythematosus in relation to serum complement concentrations. Clinical and Experimental $\$ Immunology, 25, 418.

Cathcart, E.S., Idelson, B.A, Scheinberg, M.A. \& COUSER, W.G. (1976) Beneficial effects of methyl prednisolone 'pulse' therapy in diffuse proliferative lupus nephritis Lancet, i, 163.

Cohen, A.S. \& CANosa, J.J. (1972) Criteria for the classification of systemic lupus erythematosus - status 1972 Arthritis and Rheumatism, 15, 540.

Cohen, A.S., Reynolds, W.E. \& Frankin, E.C. (1971) Preliminary criteria for the classification of systemic lupus erythematosus Bulletin on Rheumatic Diseases, 21, 643.

Davis, P., Atkins, B., Josse, R.G. \& Hughes, G.R.V. (1973) Criteria for classification of S.L.E. British Medical Journal, . 3,90 .

Dubois, E.L. \& Tuffanelli, D.L. (1964) Manifestations of $\vec{\omega}$ systemic lupus erythematosus. Journal of the American Medical Association, 190, 104.

EPSTEIN, W.V. (1973) Immunological events preceeding clinical exacerbation of systemic lupus erythematosus. in American Journal of Medicine, 54, 631 .

Estes, D. \& Christian, C.L. (1971) The natural history of systemic lupus erythematosus by prospective analysis. o Medicine, 50, 85.

Feng, P.H., Cheah, P.S. \& LeE, Y.K. (1973) Mortality in N systemic lupus erythematosus: a ten year review. British 으 Medical Journal, 4, 772.

Gary, N.E., Maher, J.F. \& Schreiner, G.E. (1967) Lupus $\vec{c}$ nephritis: renal function after prolonged survival. New England Journal of Medicine, 276, 73.

HugHes, G.R.V. (1975) Antinuclear antibodies in S.L.E. clinical and pathological significance. Clinics in Rheumate $\log y, 1,545$.

Jones, J V., Cumming, R.H., Bucknall, R.C., Asplin, C.M尺ि Fraser, I.D., Bothamley, J., Davis, P. \& Hamblin, T $\Phi$ (1976) Plasmapheresis in the management of acuex. systemic lupus erythematosus? Lancet, i, 709.

LEVINSKY, R.J., CAMERoN, J.S. \& SoOThILl, J.F. (197\%) Serum immune complexes and disease activity in lupus nephritis. Lancet, i, 564.

Pollack, V.E., Pirani, C.L., Dujovne, I. \& Dillard, M.G. (1973) In: Glomerulonephritis, p. 1167. (Kincard-Smith, P., Mathew, T.H , Lovell-Becker, E, Eds.). John Wiley \& Sons. New York, London, Sydney, Toronto.

Pollack, V.E., Pirani, C.L. \& Kark, R.M. (1961) Effect of large doses of prednisone on the renal lesions and life span of patients with lupus glomerulonephritis. Journal of Laboratory and Clinical Medicine, 57, 495.

Ponticelli, C., Imbasciati, E., BrancaCcio, D., Tarantino, A. \& Rivolta, E. (1974) Acute renal failure in systemic lúpus erythematosus. British Medical Journal, 3, 716.

SharP, G.S., IRvin, W.C., Laroque, R.L., Velez, C., 㝋 Daly, V., Kaiser, A.D. \& Holman, H.R. (1971) Asscciation of autoantibodies to different nuclear antigens $\bigcirc$ with clinical patterns of rheumatic disease and responsiveness to therapy. The Journal of Clinical Investigation, 50, 350.

Schur, P.H. (1975) Complement in lupus. Clinics in Rheumatic Diseases, 1, 519.

SCHUR, P.H. \& SANDERSON, J. (1968) Immunological factors and clinical activity in lupus erythematosus. New England $\mathrm{N}$ Journal of Medicine, 278, 533.

Urowitz, M.B., Bookman, A.A.M., Koehler, B.E., N Duncan, A.G., Smythe, H.A. \& Ogryzlo, M.A. (1976) N The bimodal mortality pattern of systemic lupus erythe- $\sigma$ matosus. The American Journal of Medicine, 60, 221.

Zweiman, B., Kornblum, J., Cornog, J. \& Hildreth, E.A. (1968) The prognosis of lupus nephritis. Annals of Internal Medicine, 69, 441 . 